\title{
Motives and Experiences of the Competent Supervisor in General Practice - A Qualitative Study
}

\author{
K. Kleizen ${ }^{1}$ and B. Mattsson ${ }^{* 2}$ \\ ${ }^{1}$ Student Department, UMC, Radboud University Nijmegen, Postbus 9101, 6500 HB Nijmegen, Holland \\ ${ }^{2}$ Department of Public Health and Community Medicine/Primary Health Care, Sahlgrenska Academy, University of \\ Gothenburg, PO Box 454, S-405 30 Gothenburg, Sweden
}

\begin{abstract}
At the Sahlgrenska Academy, University of Gothenburg, Sweden, general practitioners (GPs) teach undergraduate medical students in three stages of the curriculum. Not much is known about the GPs' motives for teaching, neither about their experiences in this process. Qualitative interviews were carried out with GPs who were known to have a positive attitude towards and interest in teaching and student supervision and assessed by the teaching-staff as skilled. The interviews were tape-recorded and transcribed. In the transcripts themes, categories and meaning units were identified according to a content analysis method. Two main themes were related to GPs' interest in teaching activities; personal issues and organizational issues. The personal issues constituted the reasons the GPs have for their positive inclination towards teaching, and consisted of early private experiences, an interest in the future, an interest in the students' development of clinical skills, and pleasure taken in teaching and personal growth. The organizational issues were the facilitating and impairing factors in the teaching process: the workload, health centre conditions and university conditions. The positive GPs who were interviewed experienced many benefits from their teaching. However, conditions could be improved regarding time and workload. Support from the health centre is an important factor in this field. The implementation of the findings to other health care systems is discussed.
\end{abstract}

Keywords: General practice, supervision, undergraduate curriculum.

\section{INTRODUCTION}

The role of general practice in medical curricula has increased and in many university courses general practitioners (GPs) are teachers of students [1-5]. Hospital-based medical training does not provide students with all the necessary knowledge, skills and attitudes. General practice adds new ingredients. Many symptom presentations in primary care are still undifferentiated and psychosocial issues occur $[6,7]$. Most GP teachers/supervisors enjoy their duties [1, 8, 9]. The skills are taught within a personalized supervision, and the students are exposed to a variety of complaints and diseases [9].

The students are generally positive to the GP attachments and a positive feedback to the teacher is common [1, 2,9]. The GPs seem to learn from their own teaching and challenging questions from students are stimulating. A positive influence on the health centre is also reported; morale is greater and the image of the practice improves $[2,8]$.

Barriers against GP attachments are described. Limited teaching ability and a lack of confidence among GP's are reported $[8,10]$. A lack of separate rooms prevents students from seeing patients alone and an established doctor-patient relationship could be disrupted by the presence of a student $[2,8]$.

*Address correspondence to this author at the Department of Public Health and Community Medicine/Primary Health Care, Sahlgrenska Academy, University of Gothenburg, PO Box 454, S-405 30 Gothenburg, Sweden; Tel: +46 7074660 52; Fax: +46 3177817 04;

E-mail: bengt.mattsson@allmed.gu.se
Most universities provide a financial reward for teaching activities. GPs' opinions about this remuneration differ greatly, but usually payment is not regarded as a motivating factor $[2,5,9]$.

At the University of Gothenburg, Sweden, GPs participate in the medical curriculum at three levels. During four early semesters students visit a GP or a hospital specialist one week every semester (Early clinical contact) [11]. The aim is to inspire students in their studies and to reflect over medical issues. The course is led by GPs. The second level $\left(5^{\text {th }}\right.$ semester) is a five-week course focusing on consultation and examination skills. The teaching takes place at health centres where students practise communication and examination skills with GPs as teachers [12]. The third level is in the final year. Students attend health centres for two weeks to do clinical work where they are supervised by GPs. Health centres in the city of Gothenburg cannot accept all students and some students travel to more remote health centres.

Most health centres in Sweden are publicly run and owned (by County Councils) implying fixed salaries to the GPs irrespective of the number of patients seen during a day. The majority of students are attached to these health centres [13]. Private health centres are usually more hesitant to students' training in the undergraduate curriculum. The task to supervise will too much encroach on the flowing through of patients.

The task as supervisor is also voluntary. Every semester inquiries are sent to health centres asking GPs for help. Over the years some GPs have been more positive and quick to 
Table 1. Interview Sample

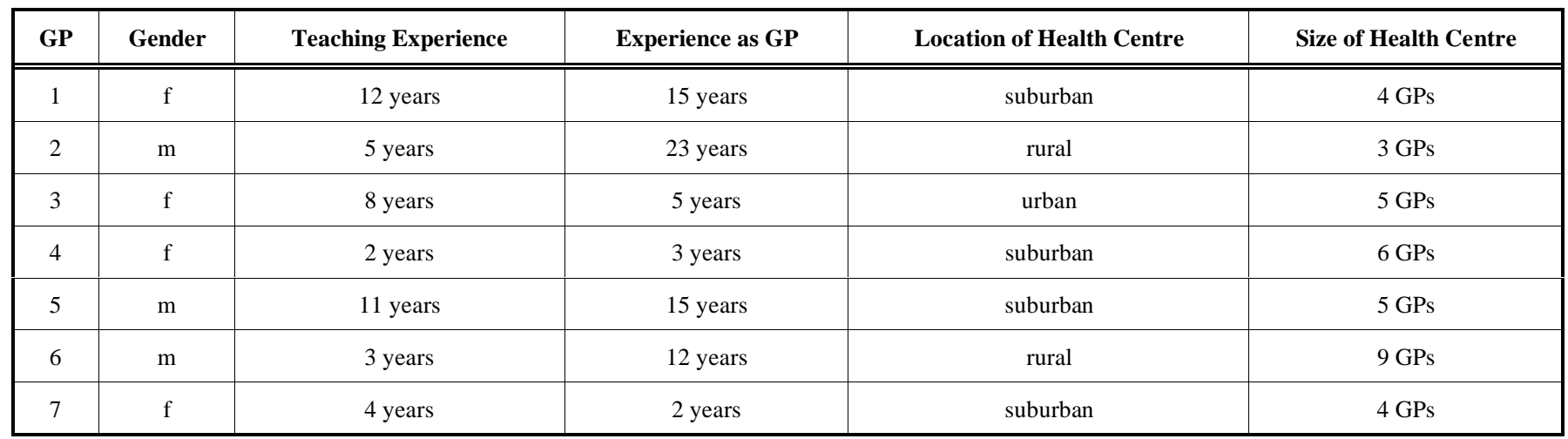

accept the role of supervisor. Usually these "positive" GPs seem to enjoy teaching and they generally receive positive feedback from the students. Once a year all supervisors are also assessed by the staff (by personal visits at the health centres or at tutorial days at the Department) and a basic quality level is needed to continue to supervise. Of course also some GPs are regarded as more or less "negative" by the staff but as the participation is optional there is a natural selection of the uninterested and less devoted GPs.

We were interested in the "positive" GPs. The recruiting of GPs could be more efficient by knowing more about the motives and incentives to their attitudes. The aim was to explore the ideas and motives of a competent and interested GP supervisor and to search for conditions that could enhance the recruitment of supervisors.

\section{MATERIALS METHODS}

GP lecturers responsible for the three GP-attachment courses were asked to nominate five GPs characterized by:

* being a frequent supervisor

* having a positive attitude towards teaching

* being well qualified according to the staff

* having received positive feedback from students

* having a helpful and supportive attitude if vacancies appear

Fifteen GPs were recruited and eight of these were purposefully selected by a senior GP. In the selection variation was sought for according to gender, working location (urban and rural areas), size of health centre and number of years of teaching experience (Table 1). One of us (BM) informed the GP supervisors initially and then the interviewer (KK) contacted the eight GPs. One did not respond. All the others agreed to take part in an interview at the health centres which lasted for 45-70 minutes. The interviewer was not known to the GPs beforehand.

The interviews were held in English and the main questions were: What are your motives for participating as a supervisor? What conditions are favourable for supervision? The initial general questions were followed by those of a more detailed nature. Clarifications and condensing were achieved by means of more targeted questions.

Initially the texts were read separately by both authors and in a number of meetings transformed units of meaning were condensed to subcategories and later grouped into categories and themes. Finally, the categories were compared with the original text to ensure they were rooted in the material $[14,15]$.

\section{RESULTS}

Two main themes appeared; personal issues and organizational issues (Table 2).

Table 2. Factors Influencing an Interest in Teaching

\begin{tabular}{|l|l|}
\hline Themes & Categories \\
\hline \hline \multirow{4}{*}{ Personal issues } & Own experiences \\
\cline { 2 - 2 } & Interest in the future \\
\cline { 2 - 2 } & Interest in students' clinical development \\
\cline { 2 - 2 } & Enjoyment \\
\cline { 2 - 2 } & Personal growth \\
\hline \multirow{5}{*}{ Organizational issues } & Workload \\
\cline { 2 - 2 } & Health centre conditions \\
\cline { 2 - 2 } & University conditions \\
\hline
\end{tabular}

\section{Personal Issues}

Four categories emerged as reasons for the GPs.

\section{Their Own Early Experiences}

Deficits in the GPs' own medical education seemed to be of importance and a lack of early practical experiences of their own was described. They were taught in a hierarchic way; patient-centredness was seldom applied and familiarity with feedback was vague.

'We didn't see any patients until the third year, we didn't have any feedback.'

\section{Interest in the Future}

The GPs stressed that future doctors needed to be well trained and GPs have an obligation to train a new generation of doctors. Future doctors also need to know more about the conditions in general practice and GPs have something to convey to all kinds of doctors. They were enthusiastic and proud of their own 'specialty'. 
"Lots of doctors don't know so much about it, so it was important for me to be part of a group that would help the students to learn about family health care."

\section{Interest in Students' Development of Clinical Skills}

The GPs encouraged the students to be confident in the doctor role. In the consultation the relational attitude was a key issue. To be familiar with clinical reasoning was also stressed. In this context the importance of giving feedback in a good and structured way was emphasized as well as the significance of the psychosocial context of many illnesses.

“...to feel secure with the knowledge and the skills they have, to feel that: yes, I can function in this role".

\section{Enjoyment}

The gains were important for both the GPs and the students. The joy of teaching influenced their willingness to participate. To see the students develop during the general practice weeks was inspiring. Mostly students were enthusiastic; the uninterested or immature students were more seldom met with. Yet it could sometimes be a challenge to train difficult students.

“..when the students go home after a day, you almost always have a feeling of satisfaction. You've had an interesting day, interesting discussions".

\section{Personal Growth}

The students usually were open and asked questions, which stimulated the GPs to reflect on their own work and practice. The tutoring compelled the GPs to be alert and be focused on teaching skills. The frequent questioning kept them up to date on medical issues and human interaction. These gains were important in the continuation of their everyday work.

"I myself learn from the students who come here, not only knowledge from their questions, but about human beings".

\section{Organizational Issues \\ Workload}

The workload for a GP was high and the teaching duties took time. You must balance between adjusting and caring for the student and paying attention to the patient. Colleagues uninterested in these teaching activities seemed to have difficulties with this equilibrium act. Supervision as a feasible task could be ranked low as it could threaten the professional role.

"Many of my colleagues are highly stressed; they don't think they have time for anything other than patients. That's what they declare".

\section{Health Centre Conditions}

The head of the centre needs to support the teaching activities as the teaching task must be assured in all occupational groups. A backing from other GPs in the centre was especially necessary. The teaching activity affected the capacity to see patients and sometimes colleagues needed to be substitutes. Support from the nurses was also vital as the nurses in many centres organized the surgeries. The information to the patients that a student will be present in the consultation must be delivered correctly. The patients usually appreciated the presence of students and few refused to be examined by a student. Only when intimate or emotional problems were involved did an unwillingness to share a private field take over.

"In this health centre it's quite easy to be a teacher, because we have a boss who is helping, who wants to have students"; "Most people are very positive towards the students".

\section{University Conditions}

The GPs and the health centres are paid by the University. This reimbursement gave some acknowledgement and compensation, and the money was usually spent for the benefit of the entire centre. The GPs seldom knew the exact amount of money except that it was rather small. A scantiness of money was never a reason for discontinuing teaching; the shortage of money was compensated by other advantages.

Training and tutorial days for the teachers are held every semester where the course objectives are highlighted the leaders of the courses being present. The GPs meet fellow teachers and appreciate seeing colleagues and discussing experiences.

“...during tutorial days we can discuss things like giving feedback, and questions that have come up during the course".

\section{DISCUSSION}

The competent supervisors displayed a mixture of personal and organizational conditions as decisive for their attitude to supervision. The teaching benefited both the students and themselves.

\section{Comments on Findings}

Some of the stated conditions have been mentioned in earlier studies. GP teachers often feel satisfied and inspired together with interested students and they are stimulated to reflect on their own practice. The teaching stimulated them to continue their own clinical duties $[2,8,16]$.

The Gothenburg GPs mentioned some motives not depicted earlier. One reason for taking part that was emphasized was to have an influence on future doctors. Their own flawed experiences of GP teaching were also referred to and their lack of early introduction to primary care was an incitement to help future colleagues.

Compared to other studies the Gothenburg teachers did not report any lack of confidence in knowledge and teaching skills $[8,10,17]$. The obvious academic support and the tutorial days might have had an impact on the self-assurance expressed. Moreover, these "positive" teachers expressed few worries about a possible negative influence on the patients. Other studies report serious concerns by the GPs about patients' reactions $[2,8,9]$. Most patients seemed to be happy to help future doctors with their training.

The time problem is mentioned earlier as spending more time with students implies less time with patients $[2,8,9]$. It has been suggested that the supervision task be reduced by half a day per week during an attachment period. The Gothenburg GPs seemed to have found ways to handle this satisfactorily. As most GPs have fixed salaries not based on the number of patients the system facilitates this possibility 
number of patients the system facilitates this possibility of exchange between students and patients.

The importance of backing from the University has been mentioned earlier and our experiences support this significance $[8,10,17]$. It is stimulating to interact with colleagues, both GPs and hospital specialists, and to be able to discuss experiences, ideas and problems. The importance of reimbursement varies in most studies; some GPs feel it is of less importance; others deprecate the cost of losing time for patient care $[5,8,9]$.

A cooperative and teaching-oriented staff in the health centre is vital for a favourable learning atmosphere and gives optimal support to the teacher. Furthermore, the competent supervisor seemed to display a certain human interest. Attention to the students' professional training and future professional role as well as a concern for their own personal growth indicate an individual approach. These features throw some light on eligible characteristics for a "positive" GP teacher.

Why some specialists perform a better job than others is depicted in a study of anaesthetists [18]. According to the author the competence is related to the way professionals understand the work. The specialist need not only to develop competence by deepening their present understanding but also by making a change of understanding, an important but difficult step in the competence development. This perspective could be perceived in the attitude of the "positive" GPs described in this study. The openness to the students' questions and curiosity reflects an access to change.

The question also arises whether the findings could be applied in other settings in other countries. The Swedish system has a main focus on publicly own health care centres, which makes it difficult to transfer the findings directly to other health care systems. Yet we think that the categories that emerged in Table $\mathbf{2}$ are applicable in other systems as well but they need to be interpreted in an appropriate and local context.

\section{Comments on Methods}

We needed a dynamic form of analysis that remained close to data. Qualitative content analysis is a systematic text analysis of data that summarizes the informal content of what is expressed in the interviews. A purposive sampling was used to reflect maximum variability of positive GPs [15, 19].

Internal validity was improved by the fact that the interviewer was an independent person unknown to the GPs and facilitates the expression of possible negative feelings by an interviewee $[15,19]$. The interviews were conducted in English, a second language for both interviewer and interviewees. Some teachers expressed concern about the language disparity. However, we do not think that the language barrier prevented them from conveying their thoughts well enough.

The preliminary findings were also presented at seminars in the Department of Primary Health Care. The interviewees were invited to take part and four of the seven GPs participated. No major objections were raised. Mainly supportive comments on the interpretations were given.

\section{CONCLUSIONS}

Both personal and organizational conditions seemed to be decisive for the interest in becoming, and the ability to be, a competent supervisor. The teaching benefited both the students and the supervisors but time and workload were impairing factors.

The competent supervisor demonstrated a strong determination and a desire to teach and the significance of giving feedback is a common denominator for this achievement. An interest in personal growth was a prime mover.

\section{ACKNOWLEDGEMENTS}

KK made the study within a research elective and her work was supported by the Network of Primary Health Care - European Exchange for Medical Students - a Socrates exchange network. BM did not receive any grants. We thank the participating interviewed GPs and Dr Peter Lucassen, Nijmegen for supervision and local support from Holland.

\section{REFERENCES}

[1] Grant A, Robling M. Introducing undergraduate medical teaching into general practice: an action research study. Med Teach 2006; 28: 192-7.

[2] Mathers J, Parry J, Lewis S, Greenfield S. What impact will an increased number of teaching general practices have on patients, doctors and medical students? Med Educ 2004; 38: 1219-28.

[3] Hastings AM, Fraser RC, McKinley RK. Student perceptions of a new integrated course in clinical methods for medical undergraduates. Med Educ 2000; 34: 101-7.

[4] Margolis SA, Davies LM, Ypinazar V. Isolated rural general practice as the focus for teaching core clinical rotations to preregistration medical students. BMC Med Educ 2005; 5: 22.

[5] Starr S, Ferguson WJ, Haley H-L, Quirk M. Community preceptors view of their identity as teachers. Acad Med 2003; 78: 820-5.

[6] Green C, Holden J. Diagnostic uncertainty in general practice. A unique opportunity for research? Eur J Gen Pract 2003; 9: 13-5.

[7] Dinant GJ, Buntinx FF, Butler CC. The necessary shift from diagnostic to prognostic research. BMC Fam Pract 2007; 8: 53.

[8] Hartley S, Macfarlane F, Gantley M, Murray E. Influence on general practitioners of teaching undergraduates: qualitative study of London general practitioner teachers. BMJ 1999; 319: 1168-71.

[9] Howe A. Teaching in practice: a qualitative factor analysis of community-based teaching. Med Educ 2000; 34: 762-8.

[10] Hartley S, Fuller J, Berlin A, et al. Teaching the teachers: the design and evaluation of a course for GP clinical skills teachers. Med Educ 1999, 33: 216-7.

[11] Hellquist G, Rödjer S, von Below B, Sveinsdottir G, Björkelund C. Early professional contact supports professional development of medical students. EPC-a new course in medical education in Gothenburg. Läkartidningen 2005; 102: 2646-8, 2650-1. (In Swedish).

[12] Wahlqvist M, Skott A, Björkelund C, Dahlgren G, Lonka K, Mattsson B. Impact of medical students' descriptive evaluations on long-term course development. BMC Med Educ 2006; 6: 24.

[13] Organisation and resources of the health service in Sweden; available from: http: //www.regeringen.se/sb/d/4114/a/26469

[14] Graneheim UH, Lundman B. Qualitative content analysis in nursing research: concepts, procedures and measures to achieve trustworthiness. Nurse Educ Today 2004; 24: 105-12.

[15] Wilson A, Williams M, Hancock B, Eds. Research approaches in primary care. Abingdon Oxon: Radcliffe Medical Press 2000; pp. $55-76$.

[16] Scott I, Sazegar P. Why community physicians teach students (or not): barriers and opportunities for preceptor recruitment. Med Teach 2006; 6: 563-5.

[17] Robinson L, Spencer J, Neal D. Teaching the teachers - a needs assessment of tutors for a new clinical skills course. Med Educ 1996; 30: 208-14. 
[18] Larson J, Holmström I, Lindberg E, Rosenqvist U. Trainee anaesthetists understand their work in different ways: implications for specialist education. Br J Anaesth 2004; 92: 381-7.
[19] Malterud K. Kvalitativa metoder i medicinsk forskning (Qualitative methods in medical research) Lund: Studentlitteratur AB 1999; (In Swedish).

Received: March 22, 2010

Revised: May 14, 2010

Accepted: May 19, 2010

() Kleizen and Mattsson; Licensee Bentham Open

This is an open access article licensed under the terms of the Creative Commons Attribution Non-Commercial License (http://creativecommons.org/licenses/by-nc/3.0/) which permits unrestricted, non-commercial use, distribution and reproduction in any medium, provided the work is properly cited. 